\title{
AWARENESS DURING SURGERY
}

\author{
James Parkhouse, M.D., F.F.A.R.C.S., D.A. \\ First Assistant, Nuffield Department of Anaesthetics, Oxford
}

Ever since Horace Wells failed to produce adequate anaesthesia with nitrous oxide on a celebrated occasion in 1844 patients have from time to time complained of being incompletely anaesthetized. In the past these unfortunate incidents were always accepted as failures, due to inexperience of the administrator, inadequacy of the apparatus or idiosyncrasy of the patient. But even today, when there is little excuse for any such failure, there are still patients who claim to have some recollection of a surgical procedure performed under general anaesthesia. ${ }^{7}$

When surgery is performed on the non-paralysed patient there is usually no doubt as to whether he is 'properly asleep' or not; his response to surgical stimulation and the absence of muscular relaxation speak for themselves. On the other hand, use of the muscle relaxants introduces new difficulties: only very small quantities of general anaesthetic agents need be used, and the classical ' signs of anaesthesia,' being muscular, are interfered with. The convention stages and planes of Guedel ${ }^{11}$ are neither recognizable nor relevant; what is required for the paralysed patient is not so much an index of anaesthetic 'depth' as an index of consciousness, and the difficulty of establishing reliable signs of ' awareness' in these circumstances is one of the greatest problems of present-day anaesthesia.

\section{Evidence of Awareness Physical Signs}

A patient who has received a clinically effective dose of d-tubocurarine chloride or gallamine may still move slightly in response to a surgical stimulus but this fact is of no value in the diagnosis of ' awareness.' Most patients who do move during surgery have no post-operative recollection of their experiences. Even more disconcerting is the fact that absence of movement does not necessarily imply lack of awareness: the author knows of a patient who 'didn't bother to try and let anybody know' although she was clearly aware of part of her operation.

After a large dose of suxamethonium the patient may be totally unable to move and any inadequacy of anaesthesia is almost certain to pass unnoticed. This danger arises when very small quantities of thiopentone are used with suxamethonium for endotracheal intubation or bronchoscopy.

Sweating, pupillary dilatation and pallor may also occur during very light anaesthesia but these are no more reliable as signs of ' awareness' than $\vec{t}$ movement. In this borderland region of consciousness in which the patient can show autonomic reflex responses and make apparently purposeful movements without post-operative recollection, the problem of amnesia is clearly important. This will be discussed in more detail below.

\section{Electroencephalographic Evidence}

The classical electroencephalographic patterng during anaesthesia relate more to the gross dif ferences between light and deep planes than to the fine shades of difference within the lighter planes themselves. The studies that have so far been made of the EEG during very light anaesthesia suggest considerable differences between the various anaesthetic agents. During very light ether anaesthesia a sequence of recognizable EEG patterns is said to correspond with diminishing ' awareness' of the patient ${ }^{2}$ but during nitrous oxide anaesthesia the patient may have a waking EEG pattern, and may even show alpha blocking when his eyes are passively opened, and yet be unable subsequently to recall any part of the operation. ${ }^{5,17}$ In any event there is no doubt that at the present time electroencephalographic evidence of awareness requires expert interpretation.

\section{Combined Evidence}

Artusio $^{3}$ uses a combination of direct physical evidence and electroencephalographic monitoring $\tilde{N}$ in order to determine the patient's level of ' aware- ్ㅗ ness.' He uses very low concentrations of ether 0 to produce what he describes as ' general analgesia , for major surgery: the patient is repeatedly asked during the course of the operation to indicate by nodding or shaking his head whether or not he is comfortable and the administration of ether is 
adjusted accordingly. From an extensive experience of this method Artusio has concluded that if the patient is sufficiently analgesic to remain comfortable during surgery total amnesia will follow the procedure. At the same time a continuous EEG tracing is interpreted by an expert.

\section{Quantitative Administration}

When muscle relaxants are not used it is unnecessary to administer predetermined concentrations of inhalational anaesthetic agents: the ' signs of anaesthesia' make it possible for the anaesthetist to adjust his dosage according to the individual requirements of each patient. When large doses of the muscle relaxants are used, quantitative methods of administration become far more important in ensuring unconsciousness.

We know that patients vary greatly in their tolerance to morphine and barbiturates and we know that some of our friends can maintain a rational conversation with a blood alcohol level that would leave others stuporous, but we know very little about individual differences in anaesthetic requirements. Gray ${ }^{10}$ reported on the administration of nitrous oxide to volunteers but he intentionally chose subjects who were all of the same physical type. In a personal study of subanaesthetic concentrations of nitrous oxide ${ }^{16}$ large variations were found in the tolerance of different subjects. The inhalational anaesthetics are unique in their manner of administration and excretion; their dosage cannot be measured in milligrams per kilogram and it is impracticable to make continuous estimations of blood level.

In the absence of reliable signs of ' awareness,' as in the paralysed patient, it is necessary to ascertain the concentration of each anaesthetic agent which will maintain unconsciousness in even the most resistant patients. If this concentration is then administered to all patients it may be assumed that none will be ' aware,' although some will be 'overdosed.' In clinical practice the concentration of anaesthetic finally to be administered must thus be decided according to the circumstances of the occasion-that is according to whether it is better to risk ' awareness ' or to risk slight ' overdosage.'

\section{The Effect of Respiration}

A notable feature of inhalational anaesthesia without the muscle relaxants is that variations in anaesthetic depth are liable to occur unless respiration continues at an absolutely constant volume and frequency. When spontaneous respiration is present, a patient who is insufficiently anaesthetized will respond to surgical stimulation by hyperventilation, thus taking greater quantities of the anaesthetic into his lungs and deepening his own anaesthesia. Conversely, when anaesthesia is deep, respiratory depression reduces the speed at which further anaesthetic can be introduced into the body. When a patient has been given a muscle relaxant he no longer has control of his own respiration and it is dangerously easy for the anaesthetist to introduce large amounts of anaesthetic into the blood stream unless quantitative apparatus is used.

It has been pointed out recently that hyperventilation, by reducing the blood carbon dioxide tension, will suppress activity in the reticular system. ${ }^{8}$ This suppression will influence consciousness and Geddes and $\mathrm{Gray}^{8}$ have produced electroencephalographic evidence to suggest that during clinical anaesthesia deliberate hyperventilation of the paralysed patient produces 'deeper' anaesthesia or, alternatively, permits the use of lower concentrations of the anaesthetie agent. It is certainly a common clinical observation that a patient who has been lying quietly on the table during controlled ventilation with nitrous oxide and oxygen will soon begin to make small movements of protest if the degree of ventilation is decreased, but whether it will be possible to establish a quantitative relationship between anaesthetic dosage, degree of ventilation and electroencephalographic pattern remains to be seen. Hyperventilation is well known to cause cerebral vasoconstriction and this may be an important contributory factor in the suppression of cerebralce activity.

\section{The Loss of Afferent Impulses}

The central nervous system receives a continuous inflow of proprioceptive discharges from the muscles of the body and the frequency of these discharges depends upon muscle tone. Complete muscular relaxation, by reducing the frequency of proprioceptive discharges from all over the body, cuts down the total afferent inflow to the central nervous system. Reduction of afferent inflow has been proposed as a mechanism of sleep, ${ }^{2 \theta}$ and altered states of consciousness are known to result when the brain is cut off from the outside world 12,14 Neurophysiological work suggests that consciousness is more a function of the non-specific projection systems related to the reticular formation than of the classical afferent pathways ${ }^{13}$ so that 'deafferentation' is no longer upheld as the sole cause of sleep or unconsciousness. It remains none the less true that an individual's level of awareness is largely influenced by the amount of information received from the periphery. Thus, although administration of a muscle relaxant will not in itself render a patient unconscious it may well produce slight differences in 'depth' of the order of magnitude under discussion. 


\section{The Significance of Stimuli}

It is possible for a conscious individual to concentrate voluntarily on certain incoming stimuli to the virtual exclusion of all others, but over and above this voluntary selection there are occasional highly ' significant' stimuli which obtrude themselves whether he wishes them to or not. The likelihood of a stimulus, or event, being remembered depends partly on the amount of attention paid to it and partly on its ' significance '; many stimuli are called into the central nervous system but few are chosen for conscious recollection.

It has often been assumed that because surgical operations are known to be painful, inadequate anaesthesia or partial 'awareness' of the patient must be associated with pain. There are both theoretical and practical reasons for believing this assumption to be false. From the theoretical point of view we know that although, to the fully alert individual, pain is often a highly ' significant' stimulus, and one to which considerable attention is paid, it is not always so. On the football field or the battlefield, for example, severe contusions may pass almost unnoticed in the excitement of the moment. Similarly, in depressed states of consciousness other forms of stimulation may have at least as much ' significance' for the individual as pain, and this is particularly true when the depression of consciousness is due to a drug with powerful analgesic properties. From the practical point of view, we know that partial ' awareness' during anaesthesia with ether, nitrous oxide and cyclopropane, all of which have analgesic effects, is not associated with any recollection of pain even when conversation is remembered in considerable detail. ${ }^{2,3,15,18}$

Most anaesthetists who have interviewed patients after episodes of ' awareness' during surgery agree about the dispassionate manner in which the experience is recalled. This might suggest repression of a terrifying experience into the subconscious, but if this were so one would expect a high incidence of anxiety states and fear of subsequent operations which is not apparent in clinical practice. The effect of a psychically traumatic experience inflicted upon a fully conscious individual is not comparable with the effect of surgical stimuli inflicted during the ' couldn't care less' state of analgesia and depressed awareness induced by anaesthetic drugs.

\section{Confusion and Amnesia}

The post-operative statements of patients provide the only real evidence of awareness during surgery and these statements are not always either forthcoming or conclusive. A patient may not complain unless specifically questioned, and it is sometimes not until a second operation is im- $\frac{\overrightarrow{0}}{\vec{N}}$ minent that the deficiencies of the previous $\varrho$ anaesthetic become known. Moreover, memory is often transient or intermittent so that a single $\supseteq$ post-operative inquiry may elicit misleading in- $\stackrel{c}{.}$ formation. If some recollection of the operative $\overrightarrow{\vec{F}}$ experience appears during the very early post $\frac{\overrightarrow{0}}{0}$ operative period it may well be 'covered' by the $\frac{\bar{O}}{0}$ amnesic effect of the anaesthetic, and will have $\frac{\bar{c}}{\bar{c}}$ disappeared completely by the following day. $\bar{\Phi}$ Some drugs used for premedication, such as scopolamine, are particularly liable to produce amnesia; this fact was exploited for the production of $\overrightarrow{0}$ 'twilight sleep.' General anaesthesia can also $\overrightarrow{ }$ produce an amnesic effect; when patients under- $\vec{\omega}$ going cordotomy are deliberately awakened during: the operation and then reanaesthetized, for 3 example, a high proportion exhibit total amnesia. Even during the early post-operative period it is not uncommon for patients to hold rational con- $\vec{N}$ versations of which they are later unaware, and $\vec{\sigma}$ this phenomenon is often related to the administra- $\rightarrow$ tion of analgesic drugs.

Occasionally a patient has been able to recall $\mathrm{a}_{\rightarrow}$ specific incident or conversation that occurred $Z$ during an operation. ${ }^{1}$ In such cases true 'awareness' cannot be doubted but many patients' recollections are so vague and illdefined that it $\frac{\mathrm{TS}}{\mathbb{Q}}$ difficult to know what, if anything, is actualB being remembered. Realistic dreams may occu during anaesthesia, as noted by Dudley Buxto 60 years ago. ${ }^{4}$ The fears uppermost in the patient's mind, whether they be fears of pain or of sexual assault, may emerge as dreams or hallucinatory experiences initiated by some trifling ac- $ڤ$ companiment of the actual surgical procedure. $\stackrel{\unrhd}{\unrhd}$ A case is known to the author in which a patient $\overrightarrow{\vec{A}}$ returned to the ward and told all her fellow patients that she had felt the whole of her operation, although the following day she realized quite clearly that what she had felt was the dressing being applied to her abdomen.

\section{Conclusions}

There have been several recent reports of ' awareness' during general anaesthesia, which have been of a nature hardly likely to inspire con- 음 fidence in the anaesthetist's colleagues or pros- $D$ pective patients. ${ }^{9}, 19$ At least one of these reports has been quoted by the lay press, ${ }^{6}$ so that an explanation of the modern anaesthetist's pro- $\infty$ blems, in reasonable perspective, may not be $\tilde{O}$ untimely.

The use of muscle relaxants has created new difficulties by abolishing the classical signs of anaesthesia and by tempting anaesthetists to use $\underset{\Phi}{\overparen{D}}$ minimal quantities of anaesthetic drugs, but it $\stackrel{\oplus}{+}$ should not be forgotten that it is the avoidance of 7 
deep general anaesthesia which has made many surgical advances possible. The anaesthetist's duty is to enable the surgeon to perform his operation without inflicting pain on the patient. This does not necessarily imply that the patient will be unconscious, and many thousands of patients have tolerated surgery under spinal or local anaesthesia without complaint. Most general anaesthetic agents are powerful analgesics so that even if a patient is not totally unaware of his surroundings it is still unlikely that he will feel pain. The deliberate use of ether and nitrous oxide to produce a state of 'general analgesia' serves to illustrate the fact that there is nothing intrinsically wrong in a patient maintaining some degree of ' awareness' during an operation as long as the situation is understood and controlled. It is clearly unreasonable to employ such methods without the full co-operation of the surgeon, who must be made aware that anything he says may be remembered by the patient.

Even after paralysing doses of curare, ' awareness' is not necessarily a terrifying experience as long as adequate ventilation is maintained. Many patients with long lasting paralysis, such as those with poliomyelitis, polyneuritis or tetanus treated with curare, tolerate artificial ventilation of the lungs without anaesthesia. Furthermore, the post-operative comments of inadequately anaesthetized patients suggest nothing in the way of alarm; indeed, respiratory paralysis has often been quite unnoticed by them.

It is always possible to ensure that a patient is completely unaware of what takes place in the operating theatre, but there are circumstances in $\frac{2}{z}$ which the 'danger' of some fragmentary recol- $\frac{1}{D}$ lection may justifiably be regarded as the least of $\frac{\varrho}{c}$ several evils. No anaesthetist would dispute the British Medical Fournal's ${ }^{7}$ statement that the patient's need for analgesia is paramount. However, their Editorial suggestion that total un- 흘 awareness is equally important cannot be accepted $\frac{\bar{\sigma}}{\vec{D}}$ in the light of available evidence.

\section{REFERENCES}

I. ALMENT, E. J. (1959), Brit. med. F., ii, 1258.

2. ARTUSIO, J. F. (1954), f. Pharmacol, III, 343.

3. ARTUSIO, J. F. (1955), f. Amer. med. Ass., 157, 33.

4. BUXTON, D. W. (1900), "Anaesthetics, Their Uses and Administration,' 3rd ed., p. 293, London: Lewis.

5. CLUTTON-BROCK, J. (1959), Personal communication.

6. Daily Telegraph, Oct. 23rd, 1959, p. 22, col. 4 .

7. Editorial (1959), Brit. med. F., ii, 810.

8. GEDDES, I. C., and GRAY, T. C. (1959), Lancet, ii, 4.

9. GRAFF, T. D., and PHILLIPS, O. C. (r959), F. Amer. med. 곤 Ass., 170, 2069.

10. GRAY, T. C. (1954). Ann. roy. Coll. Surg. Engl., 15, 402.

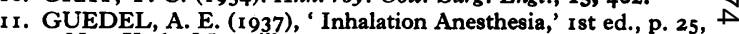
New York: Macmillan.

12. MACINTOSH, R. R. (1951), 'Lumbar. Puncture and Spinal Analgesia,' Ist ed., p.59, Edinburgh: Livingstone.

13. MAgOUN, H. W. (1950), Physiol. Rev., 30, 459.

I4. MARTIN, J. P. (1949), Lancet, i, I.

15. MENDELSOHN, D., MACDONALD, D. W., NOGUEIRA, C., and KAY, E. B. (1960), Anesth. et Analg., 39, 110.

16. PARKHOUSE, J., HENRIE, JOYCE R., DUNCAN, G. NR and ROME, H. P. (1960), $\mathcal{F}$. Pharmacol, 128, 44.

17. WALTER, W. GREY (1958), ' Modern Trends in Anaesthesio Ist ed., p.40, London: Butterworth.

18. WASMUTH, C. E., and HALE, D. E. (1954), Cleveland Cli Quart., 2I, 46.

19. WINTERBOTTOM, E. H. (1950), Brit. med. F., i, 247

20. WRIGHT, S. (1952), 'Applied Physiology,' oth ed., p. 687 , London: Oxford University Press.

\section{HOW TO GET THERE}

An Address Book for the Medical profession, showing how to reach the various Colleges, Societies, Institutes and Hospitals in or near London

New (Fifth) Edition: 1960

4s. 6d. post free

Published by the

FELLOWSHIP OF POSTGRADUATE MEDICINE

9 Great James Street, London, W.C.I 